\title{
Sensorial Design applied to teaching-learning in Artistic Drawing
}

\author{
Keywords \\ Artistic Drawing, Cognitive-behavioral Neuroscience, Neuroeducation, Sensorial Design, Visual Arts.
}

The present research focuses on the Sensorial Design approach applied to the teaching-learning of artistic drawing. The Sensorial Design is subsidized by the SEE BEYOND method [LIMA JR. G.C.; ZUANON, R. 2017-2019], which is based on cognitivebehavioral neuroscience and neuroeducation studies to develop and apply didactic-pedagogical and didactic-andragogics resources aimed at teaching and learning of Design by students with and without visual impairment. In this approach, the practice of drawing is understood as an intrinsic element to the mental mechanisms of human beings and acting in their sensorimotor, cognitive and behavioral evolution. This is because through the lines, textures, colors and other compositional elements present in the drawing practice, it is possible to elaborate or express affections and materialize emotions, sensations and thoughts, which are experienced in the mind and experienced in the body as a whole. From this understanding, the approach between the fields of artistic drawing and cognitive-behavioral neuroscience is natural. In the context of higher education, specifically in Visual Arts, the cooperation between the fields of drawing, neuroscience and neuroeducation is shown to be capable of equipping educators with pedagogical practices that contribute to the formation of contemporary artists, especially with regard to the achievement of a poetic-artistic and authorial project expression. The activities carried out from the practical approach of Sensorial Design seek to question the protagonism of vision by sensitizing and enhancing the other senses. In this process, hearing, tasting, smelling, and touching also gain prominence in the formation of mental images, unlike other teaching-learning methods in which this protagonism focuses only on vision. The Sensorial Design approach is developed in the context of higher education in Visual Arts and applied in the Artistic Drawing I and II disciplines, which are part of the Visual Arts undergraduate course's curriculum at the University of Campinas, since 2019. Through of student's somatosensory and sensorimotor stimulations, the classes address several thematic axes fundamental to the field of artistic drawing practice, which are at the base of most artistic drawing teaching programs in Brazil for example: line, contour, filling, figure, ground, movement and rhythm. From this global stimulation of the senses, students are encouraged to expand their perceptive limits and their creative processes while expanding their sensory repertoires. Furthermore, the Sensorial Design approach corroborates the rupture of pre-established visual compositional patterns and, consequently, the reach of an authorial poeticartistic expressiveness. It is important to highlight that in the period prior to the COVID-19 pandemic, all activities carried out with students took place in the face-to-face education context, and the drawing practice happened mostly through analogical instruments and mediums. With the pandemic already unleashed, such activities were adapted for distance education, in order to preserve their original characteristics, especially with regard to ensuring the application of somatosensory and sensorimotor stimulation in the students. The experience acquired along this methodological adaptation process (from face-to-face to distance education) has indicated relevant contributions to increment this approach in the post-pandemic context, e.g. to increase the number of digital media resources applied in the Sensorial Design practice, which point out to the formulation of a hybrid learning-teaching method (physical-digital). 